\title{
The quality of life following allogeneic hematopoietic stem cell transplantation - a multicenter retrospective study
}

\author{
V. VALKOVA ${ }^{1, *}$, J. JIRCIKOVA ${ }^{2}$, M. TRNKOVA ${ }^{3}$, K. STEINEROVA ${ }^{4}$, P. KESLOVA ${ }^{5}$, M. LANSKA ${ }^{6}$, Z. KORISTEK ${ }^{7}$, L. RAIDA ${ }^{8}$, M. KREJCI ${ }^{9}$, \\ K. KRUNTORADOVA ${ }^{2}$, T. DOLEZAL ${ }^{2}$, K. BENESOVA ${ }^{3}$, P. CETKOVSKY ${ }^{1}$, M. TRNENY ${ }^{3}$
}

${ }^{1}$ Institute of Haematology and Blood Transfusion, Prague; ${ }^{2}$ VALUE OUTCOMES, Prague $2 ;{ }^{3}$ Czech National Stem Cell Transplantation Registry, 1 st Dept of Medicine, Charles University General Hospital; ${ }^{4}$ Department of Hemato-Oncology, University Hospital, Plzen; ${ }^{5}$ Pediatric Hematology and Oncology, 2nd Faculty of Medicine and University Hospital Motol, Prague; ${ }^{6}$ Dept. Hematooncology, Faculty Hospital Hradec Kralove; ${ }^{7}$ Dept. of Haematooncology, University Hospital Ostrava; ${ }^{8}$ Department of Hemato-Oncology, Faculty of Medicine, Palacky University, Olomouc; ${ }^{9}$ University Hospital and Clinic of Haemato-Oncology, Brno

*Correspondence: veronika.valkova@uhkt.cz

Received November 11, 2015 / Accepted March 23, 2016

\begin{abstract}
Although allogeneic haematopoietic stem cell transplantation (allo-HSCT) offers a unique curative potential, it may be connected with high treatment-related morbidity and mortality. Besides many organ complications, allo-HSCT may significantly affect quality of life (QOL).

Patients and methods: Between January 2011 and December 2012, five hundred and ninety patients (pts) from 6 transplant centers in the Czech Republic filled in the questionnaire for the quantitative measurement of QOL using Functional Assessment of Cancer Therapy-General (FACT-G) version 4. Study cohort characteristics were as follows: 325 males, 340 pts received myeloablative conditioning, 383 pts received PBPC, representation of diagnoses; acute leukemia $(n=270)$, bone marrow failure $(n=36)$, chronic myeloid leukemia $(n=74)$, myelodysplastic/myeloproliferative syndrom $(n=110)$, lymphoproliferative disease $(n=93)$. The median age at allo-HSCT was 43 years (range: $1.7-71.0)$, the median time from allo-HSCT to questionnaire completing was 3.8 years (range: $-0.2-21.6$ ). The earliest allo-HSCT was performed in November 1989, the last in September 2012. In this retrospective study, we investigated the impact of various factors on the QOL after alloHSCT: age, gender, diagnosis, type of conditioning, time from diagnosis to allo-HSCT, disease stage, graft type, donor type, time from allo-HSCT to questionnaire completing, GVHD, relapse. Only data from patients who were more than 3 months after allo-HSCT were used for the multivariate analysis.

The overall results of the total FACT-G score (median=85.0; range: 29-108) as well as the results of each specific dimension - PWB (median=23.0; range: 5-28), SWB (median=24.0; range: 7-28), EWB (median= 19.0; range: 4-24), FWB (mean=21.0; range: 2-28) showed a value in the highest quartile of the possible evaluation. In multivariate analysis, an inferior QOL score was reported for patients with aGVHD ( $\mathrm{p}=0.002)$, cGVHD $(\mathrm{p}<0.001)$, QOL decreased with increasing age $(\mathrm{p}=0.048)$ and increased with time elapsed since allo-HSCT $(\mathrm{p}<0.001)$.

Allogeneic HSCT represents an important intervention into the overall integrity of the organism. In particular, the development of GVHD can cause very serious organ, but also mental problems which can significantly reduce the QOL. The QOL is steadily increasing with increasing interval from allo-HSCT but improvement and disappearance of these complications may take many years, and sometimes these effects may probably persist permanently.
\end{abstract}

Key words: QOL, allogeneic, transplantation, FACT-G

Allogeneic hematopoietic stem cell transplantation (allo-HSCT) has become a standard method of treatment in various malignant or non-malignant hematological diseases. Although allo-HSCT offers a unique curative potential, it may be connected with high treatment-related morbidity and mortality. The most common complications after allo-
HSCT are: organ toxicity, infections, infertility or secondary cancers, but one of the most important factor influencing the course after allo-HSCT is graft-versus-host disease (GVHD). Thirty to ninety per cent of patients develop acute or chronic GVHD which may significantly impair their health status. Thanks to advances in the understanding of many mecha- 
nisms and improvement of supportive care, the survival rates have increased in recent years. Therefore, more attention logically focuses on the quality of life (QOL). Several factors were described to be associated with physical or emotional problems after allo-HSCT; age at allo-HSCT, sex, transplant type, conditioning type, time after allo-HSCT, GVHD, relapse and many others.

In clinical practice, a negative impact on QOL is often considered as less important than the cure of the disease by transplant physicians but this view is not always accepted by the patients [1]. Significant effort should therefore be focused on better implementation of how patients and physicians use the data regarding QOL after allo-HSCT in clinical practice [2]. Our goal was to perform a nationalwide analysis of QOL in terms of the individual factors that may affect the course after

Table 1. Patient's characteristics

\begin{tabular}{|c|c|c|c|}
\hline Parameter & & $\mathrm{N}$ & $\%$ \\
\hline Total number of patients & & 590 & 100.0 \\
\hline \multirow[t]{2}{*}{ Gender } & Males & 325 & 55.1 \\
\hline & Females & 265 & 44.9 \\
\hline \multirow[t]{6}{*}{ Diagnosis } & Acute leukemia & 270 & 45.8 \\
\hline & $\mathrm{BMF}$ & 36 & 6.1 \\
\hline & CML & 74 & 12.5 \\
\hline & MDS/MPS & 110 & 18.6 \\
\hline & Lymphoproliferation & 93 & 15.8 \\
\hline & Others & 7 & 1.2 \\
\hline \multirow[t]{6}{*}{ Age (years) } & $(0 ; 18)$ & 78 & 13.2 \\
\hline & $<18 ; 30)$ & 88 & 14.9 \\
\hline & $<30 ; 40)$ & 82 & 13.9 \\
\hline & $<40 ; 50)$ & 136 & 23.1 \\
\hline & $<50 ; 60)$ & 153 & 25.9 \\
\hline & $<60 ; 70)$ & 53 & 9.0 \\
\hline \multirow{5}{*}{$\begin{array}{l}\text { Time from diagnosis to allo- HSCT } \\
\text { (years) }\end{array}$} & $(0 ; 1)$ & 356 & 60.3 \\
\hline & $<1 ; 2)$ & 94 & 15.9 \\
\hline & $<2 ; 3)$ & 41 & 6.9 \\
\hline & $<3 ; 5)$ & 36 & 6.1 \\
\hline & $<3: 23.3)$ & 63 & 10.7 \\
\hline \multirow[t]{4}{*}{ Disease stage at allo-HSCT } & early & 337 & 57.1 \\
\hline & intermediate & 129 & 21.9 \\
\hline & advance & 76 & 12.9 \\
\hline & NA & 48 & 8.1 \\
\hline \multicolumn{4}{|c|}{$\begin{array}{l}\text { Time from allo-HSCT to questionnaire } \\
\text { completing after HSCT }\end{array}$} \\
\hline \multirow[t]{3}{*}{ (days) } & (before;14) & 57 & 9.7 \\
\hline & $<14 ; 100)$ & 23 & 3.9 \\
\hline & $<100 ; 365)$ & 73 & 12.4 \\
\hline \multirow[t]{4}{*}{ (years) } & $<1 ; 2)$ & 74 & 12.5 \\
\hline & $<2 ; 3)$ & 37 & 6.3 \\
\hline & $<3 ; 5)$ & 86 & 14.6 \\
\hline & $<5 ; 21.6)$ & 240 & 40.7 \\
\hline
\end{tabular}

$\mathrm{BMF}=$ bone marrow failure, $\mathrm{CML}=$ chronic myeloid leukemia, MDS/MPS $=$ myelodysplastic/myeloproliferative disease, allo-HSCT $=$ allogeneic hemat opoietic stem cell transplantation, $\mathrm{NA}=$ not available
allo-HSCT using standardized questionnaire - the Functional Assessment of Cancer Therapy-General (FACT-G) [3], with prospective and retrospective part. Here we present the results of the retrospective analysis.

\section{Patients and methods}

Five hundred and ninety patients (pts) from 6 transplant centers in the Czech Republic filled in the questionnaire for the quantitative measurement of QOL between January 2011 and December 2012. The patients were enrolled during their regular visits or hospitalization at the transplant centre. Within the planned prospective study, part of the questionnaires was obtained from patients prior to or closely after allo-HSCT, due to the comparison of different time periods. In transplanted children, the questionnaires were completed only after they reached 18 years of age. QOL was measured with Functional Assessment of Cancer Therapy-General (FACT-G) version 4 [3]. Using 27 items, aspects of physical well-being (PWB), social/family well-being (SWB), emotional well-being (EWB), and functional well-being (FWB) on a scale of 0 to 4 were evaluated. Scores were summed up for a total score, with a possible range of 0-28 for $\mathrm{PWB}, 0-28$ for SWB, $0-24$ for EWB, 0-28 for FWB and 0-108 for a total FACT-G score. Higher total FACT-G score indicates better QOL. Evidence of relevance and validity of the FACT-G has been proven in a number of studies [4-6]. Comparison of the FACT-BMT questionnaire [7], which reflects BMT (bone marrow transplant)-specific concerns, with the FACT-G questionnaire suggested that FACT-G is less burdening and sufficient without the need for the FACT-BMT subscale for patients after allo-HSCT [8].

All methods of data collection and analysis were approved by the Institutional Review Board, and the patients gave signed informed consent.

Statistical analysis was performed on the set of all 590 patients in order to compare QOL at different time periods in relation to allo-HSCT. However, only those patients who were at least 3 months after allo-HSCT were included in the detailed analysis. The patients who had missing data in the analyzed variables were excluded from the multivariate analysis. A total of 454 patients were therefore finally included in this analysis. Data of the characteristics of initial patients' cohort are summarized in Tables 1 and 2.

The median age at time of allo-HSCT was 43 years (range; 1.7 - 71.0), the median time from allo-HSCT to questionnaire completing was 3.8 years (range; $-0.2-21.6$ ). The earliest allo-HSCT was performed in November 1989, the last in September 2012.

Definitions. Acute graft-versus-host disease (aGVHD) and chronic graft-versus-host disease (cGVHD) were evaluated according to the consensual criteria $[9,10]$. Since a significant number of patients were transplanted long before the introduction of the new classification of cGVHD [11], cGVHD scoring was performed according to the old classification [10]. Only those patients who survived for 100 days after transplantation could be evaluated for chronic GVHD. The 
Table 2. Characteristics of patients after allo-HSCT $(n=533)$

\begin{tabular}{|c|c|c|c|}
\hline Parameter & & $\mathrm{N}^{*}$ & $\%$ \\
\hline \multirow[t]{3}{*}{ Conditioning } & & 528 & \\
\hline & myeloablative & 340 & 64.4 \\
\hline & reduced intensity & 188 & 35.6 \\
\hline \multirow[t]{3}{*}{ Donor } & & 533 & \\
\hline & related & 209 & 39.2 \\
\hline & unrelated & 324 & 60.8 \\
\hline \multirow[t]{4}{*}{ Graft } & & 533 & \\
\hline & bone marrow & 143 & 26.8 \\
\hline & PBPC & 383 & 71.9 \\
\hline & others & 7 & 1.3 \\
\hline \multirow[t]{3}{*}{ TBI } & & 532 & \\
\hline & yes & 167 & 31.4 \\
\hline & no & 365 & 68.6 \\
\hline \multirow[t]{3}{*}{ Relaps after allo-HSCT } & & 533 & \\
\hline & yes & 66 & 12.4 \\
\hline & no & 467 & 87.6 \\
\hline \multirow[t]{5}{*}{ Acute GVHD } & & 522 & \\
\hline & no & 286 & 54.8 \\
\hline & grade I & 62 & 11.9 \\
\hline & grade II & 151 & 28.9 \\
\hline & grade III-IV & 23 & 4.4 \\
\hline \multirow[t]{5}{*}{ Chronic GVHD } & & 510 & \\
\hline & no & 287 & 56.3 \\
\hline & limited & 118 & 23.1 \\
\hline & extensive & 101 & 19.8 \\
\hline & NA & 4 & 0.8 \\
\hline \multirow[t]{4}{*}{ Duration of cGvHD } & & 215 & \\
\hline & $<1$ year & 76 & 35.3 \\
\hline & 1- 2 years & 36 & 16.7 \\
\hline & $\geq 2$ years & 103 & 47.9 \\
\hline \multirow[t]{4}{*}{${ }^{*} \mathrm{cGVHD}$ in last 6 months } & & 510 & \\
\hline & yes & 126 & 24.7 \\
\hline & no & 380 & 74.5 \\
\hline & NA & 4 & 0.8 \\
\hline
\end{tabular}

$\overline{\mathrm{N}^{*} \text { - number of evaluable patients, } \mathrm{PBPC}=\text { peripheral blood progenitor stem }}$ cells, $\mathrm{TBI}=$ total body iradiation, $\mathrm{GVHD}=$ graft-versus host disease, $\mathrm{NA}=$ not available, allo-HSCT $=$ allogeneic hematopoietic stem cell transplantation, ${ }^{*}$ cGVHD in last 6 months = active cGVHD symptoms in the period of up to 6 months prior to filling in the questionnaire

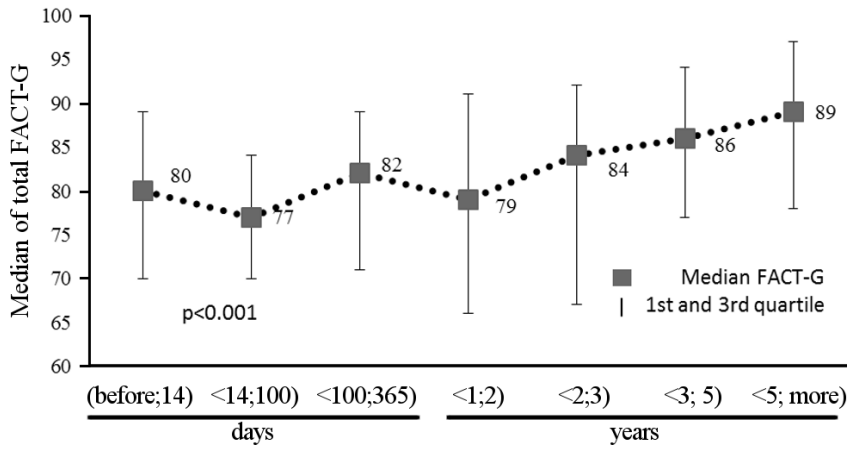

Figure 1. Total FACT-G score at different time periods before and after allo-HSCT $(n=590)$. The total FACT-G score is presented by median and lower and upper quartile around median in error bars. Differences between medians of FACT-G in 7 time periods was tested by non-parametric Kruskal-Wallis test and were significant $(p<0.001)$

cGVHD duration was defined as the interval from the date of cGVHD diagnosis to the date of withdrawal of systemic immunosuppression. Disease stage was defined according to adapted EBMT criteria [12].

Statistical analysis. Statistical analysis was performed using STATA software version 11.0 and $\mathrm{R}$ software version 2.15.2. Descriptive statistics was performed to evaluate the dataset and there is presented a number and proportion of patients in each categories. Quality of life of patients in each of the groups was expressed through the mean, standard deviation, median, minimum and maximum values. The differences between two groups of patients were tested using non-parametric Wilcoxon two-sample test or parametric two-sample t-test. The non-parametric Kruskal- Wallis test was always used for testing the difference between three or more groups. Parametric tests were used if the assumption such as normal distibution of data and homogeneity of variances were met. All statistical tests were evaluated on the 5\% level of significance. The influence of age, aGVHD, cGVHD, time from transplantation to completion of the questionnaire, diagnosis, disease status at transplantation, gender, and total body irradiation on quality of life was investigated using multivariate regression analysis. The selection of variables was based on the selection of variables of interest, which should not be omitted

Table 3. Overall results of FACT-G and each dimension

\begin{tabular}{|c|c|c|c|c|c|c|c|c|}
\hline \multirow{6}{*}{ 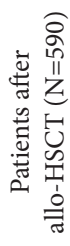 } & \multicolumn{2}{|l|}{ Parameter } & $\mathrm{N}^{*}$ & Mean & $\mathrm{SD}$ & Median & Min & Max \\
\hline & Physical well-being & PWB & 590 & 21.9 & 5.2 & 23.0 & 5.0 & 28.0 \\
\hline & Social /family well-being & SWB & 588 & 23.0 & 4.1 & 24.0 & 7.0 & 28.0 \\
\hline & Emotional well-being & EWB & 586 & 18.0 & 4.1 & 19.0 & 4.0 & 24.0 \\
\hline & Functional wel-being & FWB & 588 & 20.5 & 5.2 & 21.0 & 2.0 & 28.0 \\
\hline & Total score & FACT-G & $590^{2}$ & 83.4 & 14.4 & 85.0 & 29.0 & 108.0 \\
\hline
\end{tabular}

$\mathrm{N}^{*}$ - number of patients with available data, $\mathrm{PWB}=$ physical well-being, $\mathrm{SWB}=$ social/family well-being, $\mathrm{EWB}=$ emotional well-being, $\mathrm{FWB}=$ functional well being, patients were included according overall score (FACT-G) criteria counted from all sub-categories $(24,25)$ 
in the model, and variables which are significant or correlated with QOL. One-dimensional and two-dimensional exploratory analysis was performed. The multivariate analysis used a linear regression model.

\section{Results}

The median of total FACT-G results as well as the median of results in each specific dimension ranged from the upper $25 \%$ of the possible evaluation (Table 3 ).
The overall attained QOL score significantly varied depending on the time interval from allo-HSCT. The total FACT-G score achieved at different periods in relation to allo-HSCT is shown in Figure 1. We observed a lower total FACT-G score immediately after allo-HSCT, with subsequent higher score after 100 days, followed by lower score in the period between 1-2 years, and then a sustained increase (the score of total FACT-G reached $73 \%$ after one year, $80 \%$ after 3 years and $82 \%$ of the maximum values after 5 years). In terms of domains of FACT-G, a similar trend was observed in the range

Table 4. Univariate analysis of total FACT-G according to the individual factors $(n=454)$

\begin{tabular}{|c|c|c|c|c|c|c|c|c|}
\hline \multicolumn{2}{|l|}{ Parameter } & \multirow{2}{*}{$\frac{\mathrm{N}^{*}}{51}$} & \multirow{2}{*}{$\begin{array}{c}\text { mean } \\
88.4\end{array}$} & \multirow{2}{*}{$\begin{array}{c}\text { SD } \\
12.9\end{array}$} & \multirow{2}{*}{$\begin{array}{c}\text { median } \\
90.0\end{array}$} & \multirow{2}{*}{$\begin{array}{l}\min \\
47.0\end{array}$} & \multirow{2}{*}{$\begin{array}{c}\text { Max } \\
108.0\end{array}$} & \multirow{2}{*}{$\frac{p \text {-value }}{<0.001}$} \\
\hline Age (years) & $(0 ; 18)$ & & & & & & & \\
\hline & $<18 ; 30)$ & 68 & 87.3 & 11.6 & 89.0 & 49.0 & 106.0 & \\
\hline & $<30 ; 40)$ & 64 & 83.9 & 13.1 & 84.0 & 57.0 & 108.0 & \\
\hline & $<40 ; 50)$ & 111 & 82.5 & 14.6 & 84.0 & 42.0 & 108.0 & \\
\hline & $<50 ; 60)$ & 128 & 80.2 & 16.3 & 81.5 & 29.0 & 108.0 & \\
\hline & $<60 ; 70)$ & 32 & 84.8 & 17.5 & 88.0 & 48.0 & 108.0 & \\
\hline \multirow[t]{2}{*}{ Gender } & female & 202 & 84.6 & 13.6 & 86.0 & 42.0 & 108.0 & ns \\
\hline & male & 252 & 82.8 & 15.6 & 85.5 & 29.0 & 108.0 & \\
\hline \multirow[t]{4}{*}{ Diagnosis } & $\mathrm{AL}$ & 218 & 82.8 & 14.2 & 85.0 & 34.0 & 108.0 & ns \\
\hline & CML & 73 & 84.6 & 15.2 & 88.0 & 37.0 & 108.0 & \\
\hline & MDS/MPS & 89 & 85.7 & 15.6 & 87.0 & 29.0 & 107.0 & \\
\hline & lymphoproliferation & 74 & 82.3 & 14.9 & 86.5 & 48.0 & 108.0 & \\
\hline \multirow[t]{2}{*}{ Conditioning } & myeloablative & 301 & 84.4 & 14.5 & 86.0 & 29.0 & 108.0 & ns \\
\hline & reduced intensity & 152 & 82.1 & 15.1 & 84.0 & 42.0 & 108.0 & \\
\hline \multirow[t]{2}{*}{ Donor } & related & 169 & 85.1 & 14.0 & 88.0 & 46.0 & 108.0 & ns \\
\hline & unrelated & 285 & 82.7 & 15.2 & 85.0 & 29.0 & 108.0 & \\
\hline \multicolumn{2}{|c|}{ Disease stage at allo-HSCT } & & & & & & & ns \\
\hline & early & 285 & 84.3 & 14.8 & 86.0 & 29.0 & 108.0 & \\
\hline & intermediate & 111 & 82.5 & 14.3 & 83.0 & 48.0 & 108.0 & \\
\hline & advance & 58 & 82.2 & 15.5 & 86.0 & 42.0 & 106.0 & \\
\hline \multirow[t]{2}{*}{ Graft } & bone marrow & 118 & 85.8 & 14.8 & 88.5 & 37.0 & 108.0 & 0.030 \\
\hline & PBPC & 332 & 82.7 & 14.7 & 84.5 & 29.0 & 108.0 & \\
\hline \multirow[t]{2}{*}{ TBI } & yes & 148 & 85.1 & 13.7 & 87.0 & 29.0 & 108.0 & ns \\
\hline & no & 306 & 82.9 & 15.2 & 85.5 & 34.0 & 108.0 & \\
\hline \multicolumn{2}{|c|}{ Diagnosis- allo-HSCT interval (years) } & & & & & & & ns \\
\hline & $(0 ; 1)$ & 263 & 83.0 & 15.3 & 85.0 & 29.0 & 108.0 & \\
\hline & $<1 ; 2)$ & 80 & 85.6 & 13.2 & 89.0 & 55.0 & 108.0 & \\
\hline & $<2 ; 3)$ & 37 & 85.6 & 14.6 & 84.0 & 52.0 & 108.0 & \\
\hline & $<3 ; 5)$ & 28 & 83.0 & 14.5 & 86.5 & 54.0 & 103.0 & \\
\hline & $<3 ; 23.3)$ & 46 & 82.5 & 14.5 & 86.0 & 46.0 & 107.0 & \\
\hline \multicolumn{2}{|c|}{ Relaps after allo-HSCT } & & & & & & & ns \\
\hline & yes & 57 & 83.5 & 14.1 & 81.0 & 48.0 & 108.0 & \\
\hline & no & 397 & 83.6 & 14.9 & 86.0 & 29.0 & 108.0 & \\
\hline \multicolumn{3}{|c|}{ Time from allo-HSCT to questionnaire completing } & & & & & & $<0.001$ \\
\hline (days) & $<100 ; 365)$ & 71 & 80.9 & 13.4 & 82.0 & 49.0 & 107.0 & \\
\hline \multirow[t]{4}{*}{ (years) } & $<1 ; 2)$ & 64 & 77.8 & 16.6 & 78.5 & 42.0 & 108.0 & \\
\hline & $<2 ; 3)$ & 34 & 81.1 & 17.4 & 85.0 & 34.0 & 105.0 & \\
\hline & $<3 ; 5)$ & 80 & 84.2 & 12.3 & 85.0 & 46.0 & 107.0 & \\
\hline & $<5 ; 21.6)$ & 205 & 86.5 & 14.4 & 89.0 & 29.0 & 108.0 & \\
\hline
\end{tabular}

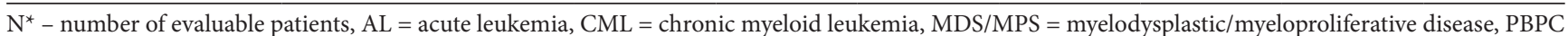
$=$ peripheral blood progenitor stem cells, $\mathrm{TBI}=$ total body iradiation 
of PWB ( $<<0.001)$, whereas in SWB we observed a slightly higher score in the period immediately after allo-HSCT up to 100 days, with the largest drop in the period 1-2 years after allo-HSCT, and then a steady increase to the pre-transplant values $(\mathrm{p}=0.040)$.

The EWB showed higher scores in the close post-transplant period up to 1 year after allo-HSCT, lower scores in the period 1-2 years after allo-HSCT and then sustained increase (from base value of $67 \%$ at time of allo-HSCT to $79 \%$ of maximum values after 3 years, $\mathrm{p}=0.002$ ). In the FWB our data indicate a lower score immediately after allo-HSCT, followed by gradual score increase $(\mathrm{p}<0.001)$.

In univariate analysis (Table 4) female patients reported a higher score in the SWB area $(\mathrm{p}<0.001)$, but there was no difference in the total FACT-G score in terms of gender.

Statistically significant differences were observed in terms of age at the time of allo-HSCT; a higher score has been reported in younger patients in the area total FACT-G $(\mathrm{p}<0.001)$, in the PWB $(\mathrm{p}<0.001)$ and FWB $(\mathrm{p}<0.001)$, while no significant differences were observed in the area EWB and SWB.

Sixty-two (13.7\%) patients from the analysed cohort developed aGVHD grade I, one hundred thirty $(28.6 \%)$ pts grade II and seventeen (3.7\%) pts developed aGVHD grade III or IV. Significantly decreased QOL in the PWB, EWB, FWB area and total FACT-G was observed in patients with aGVHD grade II and worse (Table 5).

A total of 200 evaluable patients developed chronic GVHD (Table 6), which significantly worsened QOL score in all the areas (PBW, SWB, EWB, FWB and total FACT-G).

We did not observe a significant difference between the limited and extensive cGVHD form; similarly, there was no difference in terms of the total duration of cGVHD (median duration of cGVHD was 1.6 years).

However, significantly inferior QOL scores in the PWB $(\mathrm{p}=0.004), \mathrm{FWB}(\mathrm{p}=0.001)$ and total FACT-G $(\mathrm{p}=0.003)$ areas have been reported by those patients who had cGVHD in the period of up to 6 months prior to filling in the questionnaire.

A higher score of total FACT-G was observed in patients transplanted with bone marrow compared to PBPC (peripheral blood progenitor stem cells) ( $\mathrm{p}=0.020)$.

On the other hand, the following parameters were not statistically significant in univariate analysis: type of donor (related versus unrelated), type of conditioning regimen (myeloablative versus reduced-intensity), type of diagnosis, relapse, time from diagnosis to allo-HSCT or the use of total body irradiation (TBI) within the conditioning. With the exception of patients with chronic myeloid leukemia, where

Table 5. FACT-G according acute GVHD

\begin{tabular}{|c|c|c|c|c|c|c|c|}
\hline & Parameter & aGvHD & $\mathrm{N}^{*}$ & Mean & $\mathrm{SD}$ & Median & $\mathrm{p}$-value \\
\hline \multirow{20}{*}{ 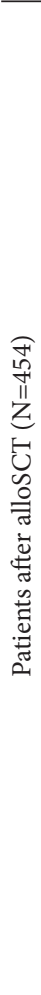 } & \multirow[t]{4}{*}{ PWB } & Grade 0 & 245 & 22.6 & 5.1 & 24.0 & 0.003 \\
\hline & & Grade I & 62 & 22.9 & 4.5 & 24.0 & \\
\hline & & Grade II & 130 & 20.9 & 5.4 & 22.0 & \\
\hline & & Grade III + IV & 17 & 19.5 & 6.4 & 20.0 & \\
\hline & \multirow[t]{4}{*}{ SWB } & Grade 0 & 245 & 23.1 & 4.5 & 24.0 & 0.162 \\
\hline & & Grade I & 62 & 23.0 & 4.3 & 23.5 & \\
\hline & & Grade II & 128 & 22.5 & 3.9 & 23.0 & \\
\hline & & Grade III + IV & 17 & 22.6 & 4.2 & 23.0 & \\
\hline & \multirow[t]{4}{*}{ EWB } & Grade 0 & 243 & 18.6 & 4.0 & 19.0 & 0.005 \\
\hline & & Grade I & 62 & 18.8 & 3.9 & 20.0 & \\
\hline & & Grade II & 129 & 17.0 & 4.6 & 18.0 & \\
\hline & & Grade III + IV & 17 & 18.2 & 3.8 & 19.0 & \\
\hline & \multirow[t]{4}{*}{ FWB } & Grade 0 & 245 & 20.9 & 5.2 & 21.0 & 0.003 \\
\hline & & Grade I & 62 & 21.7 & 4.7 & 22.0 & \\
\hline & & Grade II & 130 & 19.3 & 5.2 & 20.0 & \\
\hline & & Grade III + IV & 17 & 19.5 & 5.1 & 20.0 & \\
\hline & \multirow[t]{4}{*}{ FACT-G } & Grade 0 & 245 & 85.3 & 14.5 & 88.0 & $<0.001$ \\
\hline & & Grade I & 62 & 86.4 & 14.1 & 89.0 & \\
\hline & & Grade II & 130 & 79.6 & 14.6 & 79.0 & \\
\hline & & Grade III + IV & 17 & 79.8 & 15.9 & 79.0 & \\
\hline
\end{tabular}

$\mathrm{N}^{*}-$ number of patients with available data 
Table 6. FACT-G according chronic GVHD

\begin{tabular}{|c|c|c|c|c|c|c|c|}
\hline & Parameter & cGvHD & $\mathrm{N}^{*}$ & Mean & $\mathrm{SD}$ & Median & p-value \\
\hline \multirow{10}{*}{ 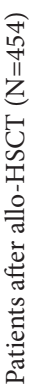 } & \multirow[t]{2}{*}{ PWB } & Yes & 200 & 20.9 & 5.4 & 21.5 & \multirow[t]{2}{*}{$<0.001$} \\
\hline & & No & 250 & 23.0 & 4.9 & 24.0 & \\
\hline & \multirow[t]{2}{*}{ SWB } & Yes & 199 & 22.5 & 4.2 & 23.0 & \multirow[t]{2}{*}{0.022} \\
\hline & & No & 249 & 23.2 & 4.3 & 24.0 & \\
\hline & \multirow[t]{2}{*}{ EWB } & Yes & 199 & 17.7 & 4.1 & 18.0 & \multirow[t]{2}{*}{0.006} \\
\hline & & No & 248 & 18.6 & 4.3 & 19.0 & \\
\hline & \multirow[t]{2}{*}{ FWB } & Yes & 200 & 19.8 & 5.3 & 20.0 & \multirow[t]{2}{*}{0.006} \\
\hline & & No & 250 & 21.1 & 5.0 & 22.0 & \\
\hline & \multirow[t]{2}{*}{ FACT-G } & Yes & 200 & 80.8 & 14.9 & 80.0 & \multirow[t]{2}{*}{$<0.001$} \\
\hline & & No & 250 & 86.0 & 14.3 & 89.0 & \\
\hline
\end{tabular}

$\mathrm{N}^{*}$ - number of patients with available data, patients were included according overall score (FACT-G) criteria counted from all sub-categories $(24,25)$

significantly inferior scores in the group of advanced disease were observed, the disease status at the time of allo-HSCT had not a significant impact on QOL.

In multivariate analysis, significantly inferior QOL score was confirmed for patients with aGVHD and with cGVHD presence in last 6 months (regardless of the extent); its significant decrease occurred with increasing age and significantly higher score was reported with the time that elapsed since allo-HSCT. In a regression model, borderline significance in terms of better QOL occurred for the diagnosis of MDS / MPS compared to the group of acute leukemias; however, the overall effect of variable "diagnosis" was not significant $(\mathrm{p}=$ 0.075) (Table 7).

\section{Discussion}

Our work represents the whole national analysis of quality of life after allogeneic transplantation in the Czech Republic,

Table 7. Multivariate analysis $(\mathrm{n}=454)$

\begin{tabular}{lcc}
\hline Parameter & estimate & p-value \\
\hline (Intercept) & 84.545 & $<2 \mathrm{e}-16$ \\
Age & -0.094 & 0.048 \\
aGVHD grade I & 0.541 & $\mathrm{~ns}$ \\
aGVHD grade II & -5.418 & $<0.001$ \\
aGVHD grade III +IV & -4.639 & $\mathrm{~ns}$ \\
cGVHD extensive (last 6 months) & -6.382 & 0.006 \\
cGVHD limited (last 6 months) & -5.440 & 0.002 \\
Time from allo-HSCT - questionnaire completing & 0.631 & $<0.001$ \\
Diagnosis CML & -1.984 & $\mathrm{~ns}$ \\
Diagnosis lymphoproliferation & 2.228 & $\mathrm{~ns}$ \\
Diagnosis MDS/MPS & 3.592 & 0.043 \\
Disease stage -intermediate & -1.826 & $\mathrm{~ns}$ \\
Disease stage advanced & -3.486 & $\mathrm{~ns}$ \\
Gender - male & -1.740 & $\mathrm{~ns}$ \\
Total body iradiation - yes & 2.868 & $\mathrm{~ns}$ \\
\hline
\end{tabular}

The analysis used a linear regression model. Adjusted R-squared: 0.124, p-value $5.458 \mathrm{e}-10$ which is very important because of all centers involved in allo-HSCT have participated.

In accordance with other studies [7, 13-18], significant differences in QOL were reported depending on the time elapsed since allo-HSCT. We observed a reduction in QOL score closely after allo-HSCT, with subsequent improvement after 100 days, another decrease between 1-2 years, where probably the greatest incidence of complications associated with cGVHD appears, and then a permanent increase of the reported values. Generally, gradual improvement can be expected in all areas of FACT-G over time, but it may take several years.

Some reports suggest a lower QOL score in women, namely lower EWB [19] and the total score [17]; we observed a higher score in the SWB area. However, in the multivariate model the influence of gender was not significant. We have demonstrated a relationship between age and QOL, younger patients reported a higher score, while the most significant border appears between patients younger than 30 years and higher age groups. Similar results were reported by other authors [17, 18, 20-22].

However, the most important complication after allo-HSCT is a graft versus host disease, which has a crucial impact on QOL in both forms - acute $[23,24]$ or chronic $[8,14,23$, 25-28].

Acute GVHD significantly contributed to the deterioration of QOL in all areas (except for SWB); significantly worse results were observed in patients with aGVHD grade II and more (compared to grade 0 and I). In our study group, chronic GVHD significantly worsened QOL in all aspects (PBW, SWB, EWB, FWB and total FACT-G). As already mentioned above, we used an older classification of cGVHD [10]; however, in terms of QOL evaluation it probably does not represent a problem, since it seems that even the current NIH classification does not reflect the full QOL experience of patients with cGVHD [8].

Regarding the extent of cGVHD and QOL, there was no significant difference between the limited and extensive form, nor did the total duration of cGVHD matter. However, signifi- 
cantly inferior QOL score in the PWB, FWB and total FACT-G areas was observed in patients with CGVHD who had active symptoms in the period within the 6 months prior to filling in the questionnaire. It seems, therefore, that regardless of the severity and duration of cGVHD, QOL is improved after its disappearance.

There are works demonstrating the influence of PBPC as stem cell source on the incidence of GVHD $[25,29,30]$. Our data also indicate a negative impact of PBPC on the QOL, probably due to a higher incidence of cGVHD, although it was not significant in multivariate analysis.

When analyzing the results in patients more than three months after allo-HSCT, we did not notice a significant difference in terms of the type of diagnosis, donor, conditioning regimen, time from diagnosis to allo-HSCT, disease stage at allo-HSCT, the use of TBI or the appearance of relapse. One possible explanation of relapse having no effect on QOL could be the fact that $70 \%$ of the 66 evaluable relapsing patients had a diagnosis of chronic myeloid leukemia, myeloproliferative syndrome or lymphoproliferative disorder where the course of the relapse may be slow and is more accessible to GVL (graft-versus leukemia / lymphoma) effect.

After more than 2 years after allo-HSCT, the median of total FACT-G score was in the top $20 \%$ of the possible maximum. We do not have the FACT-G quality of life data for normal population, so it is not possible in our study to answer the question if the QOL is getting closer to these normal values. However, when we compare the reported QOL from culturally similar region of Austria [31], their QOL FACT-G 86.6 in normal population is similar to that we observed in long term survivors in our study. Of course, it is very difficult to compare such difficult-to-measure parameter as QOL with "healthy" population, and it is very likely that it is "overestimated" by transplant patients.

The main limitation of this work is seen to be the retrospective nature of our study. The prospective study is ongoing and we have used the data of patients before allo-HSCT as the starting point. On the other side, the retrospective character allows us to include the long term survivors as well.

A linear regression model was used in the final multivariate analysis. The resulting model includes 8 selected variables (significant ones and those of interest) that most profoundly affect the final QOL after allo-HSCT. Regression modeling allowed us to express the relationship between the individual predictors and the dependent variable after eliminating the influence of other variables in the model. For this reason, model variables included in the model are, e.g., diagnosis and gender, which do not have a statistically significant effect on quality of life but their effect on other variables in the model has to be eliminated to obtain true results of the analysis. In some parameters, the data in this study are not balanced. For example, patients with a certain diagnosis completed the questionnaire only long after allo-HSCT, some parameters are typical for the childhood, etc.
Many authors describe the positive impact of the difficult life situation represented by the complications associated with alloHSCT[32-34]. This involves particularly the discovery of new life priorities, appreciation of family and partner, or strengthening and deepening of spiritual values, i.e. parameters not necessarily dependent on the functional and the overall fitness.

Our work shows that QOL in long-term surviving patients was assessed as very good. In the experiment, a number of physical exercises or psycho-social interventions have been tested in order to improve QOL after HSCT. It seems that, for example, patients who participated in regular exercise under expert supervision reported better QOL in the PWB area already in the early post-transplant period $[35,36]$. Coping skills training in the field of psycho-social interventions is probably more complicated but it represents an area for further possible improvements of total QOL after allo-HSCT. Finally we can try to draw some conclusions for patients as well for physicians.

Conclusions for patients: Although allo-HSCT can often be the only curative treatment option, it concurrently represents an important intervention into the overall integrity of the organism. In particular, the development of GVHD can cause very serious organ, but also mental problems which can then significantly reduce the overall QOL. Although gradual improvement and regression of these complications occurs it may take many years, and sometimes the effects of this treatment may persist permanently.

Conclusions for physicians: All patients should be well informed, not only about the risks of treatment failure, organ complications or possible death but also about chronic psychological consequences and the expected deterioration in the quality of life that can be finally perceived as worse than the actual disease.

Acknowledgments: The study was supported by IGA of the Czech Ministry of Health - grant No. NT 11299-6 and by Charles University in Prague, First Faculty of Medicine - program PRVOUK - P27/ LF1/1.

\section{References}

[1] PIDALA J, ANASETTI C, JIM H. Quality of life after allogeneic hematopoietic cell transplantation. Blood 2009; 114: 7-19. http://dx.doi.org/10.1182/blood-2008-10-182592

[2] NORKIN M, HSU JW, WINGARD JR. Quality of life, social challenges, and psychosocial support for long-term survivors after allogeneic hematopoietic stem-cell transplantation. Semin Hematol 2012; 49: 104-109. http://dx.doi. org/10.1053/j.seminhematol.2011.10.004

[3] CELLA DF, TULSKY DS, GRAY G, SARAFIAN B, LINN E, et al. The Functional Assessment of Cancer Therapy scale: development and validation of the general measure. J Clin Oncol 1993; 11: 570-579.

[4] BRUCKER PS, YOST K, CASHY J, WEBSTER K, CELLA D. General population and cancer patient norms for the Functional Assessment of Cancer Therapy-General 
(FACT-G). Eval Health Prof 2005; 28: 192-211. http://dx.doi. org/10.1177/0163278705275341

[5] LUCKETT T, KING MT, BUTOW PN, OGUCHI M, RANKIN N, et al. Choosing between the EORTC QLQ-C30 and FACT-G for measuring health-related quality of life in cancer clinical research: issues, evidence and recommendations. Ann Oncol 2011; 22: 2179-2190. http://dx.doi. org/10.1093/annonc/mdq721

[6] OVERCASH J, EXTERMANN M, PARR J, PERRY J, BALDUCCI L. Validity and reliability of the FACT-G scale for use in the older person with cancer. Am J Clin Oncol 2001; 24: 591-596. http://dx.doi.org/10.1097/00000421-200112000$\underline{00013}$

[7] MCQUELLON RP, RUSSELL GB, CELLA DF, CRAVEN BL, BRADY M, et al. Quality of life measurement in bone marrow transplantation: development of the Functional Assessment of Cancer Therapy-Bone Marrow Transplant (FACT-BMT) scale. Bone Marrow Transplant 1997; 19: 357-368. http:// dx.doi.org/10.1038/sj.bmt.1700672

[8] PIDALA J, KURLAND BF, CHAI X, VOGELSANG G, WEISDORF DJ, et al. Sensitivity of changes in chronic graftversus-host disease activity to changes in patient-reported quality of life: results from the Chronic Graft-versus-Host Disease Consortium. Haematologica 2011; 96: 1528-1535. http://dx.doi.org/10.3324/haematol.2011.046367

[9] PRZEPIORKA D, WEISDORF D, MARTIN P, KLINGEMANN HG, BEATTY P, et al. 1994 Consensus Conference on Acute GVHD Grading. Bone Marrow Transplant 1995; 15: $825-828$.

[10] SHULMAN HM, SULLIVAN KM, WEIDEN PL, MCDONALD GB, STRIKER GE, et al. Chronic graft-versus-host syndrome in man. A long-term clinicopathologic study of 20 Seattle patients. Am J Med 1980; 69: 204-217. http://dx.doi. org/10.1016/0002-9343(80)90380-0

[11] FILIPOVICH AH, WEISDORF D, PAVLETIC S, SOCIE G, WINGARD JR, et al. National Institutes of Health consensus development project on criteria for clinical trials in chronic graft-versus-host disease: I. Diagnosis and staging working group report. Biol Blood Marrow Transplant 2005; 11: 945-956. http://dx.doi.org/10.1016/j.bbmt.2005.09.004

[12] GRATWOHL A. The EBMT risk score. Bone Marrow Transplant 2012; 47: 749-756. http://dx.doi.org/10.1038/ bmt.2011.110

[13] BUSH NE, DONALDSON GW, HABERMAN MH, DACANAY R, SULLIVAN KM. Conditional and unconditional estimation of multidimensional quality of life after hematopoietic stem cell transplantation: a longitudinal follow-up of 415 patients. Biol Blood Marrow Transplant 2000; 6: 576-591. http://dx.doi.org/10.1016/S1083-8791(00)70067-X

[14] CHIODI S, SPINELLI S, RAVERA G, PETTI AR, VAN LINT MT, et al. Quality of life in 244 recipients of allogeneic bone marrow transplantation. Br J Haematol 2000; 110: 614-619. http://dx.doi.org/10.1046/j.1365-2141.2000.02053.x

[15] GRULKE N, ALBANI C, BAILER H. Quality of life in patients before and after haematopoietic stem cell transplantation measured with the European Organization for Research and Treatment of Cancer (EORTC) Quality of Life Core Question- naire QLQ-C30. Bone Marrow Transplant 2012; 47: 473-482. http://dx.doi.org/10.1038/bmt.2011.107

[16] BEVANS MF, MARDEN S, LEIDY NK, SOEKEN K, CUSACK $\mathrm{G}$, et al. Health-related quality of life in patients receiving reduced-intensity conditioning allogeneic hematopoietic stem cell transplantation. Bone Marrow Transplant 2006; 38: 101-109. http://dx.doi.org/10.1038/sj.bmt.1705406

[17] NIEDERBACHER S, THEM C, PINNA A, VITTADELLO F, MANTOVAN F. Patients' quality of life after allogeneic haematopoietic stem cell transplantation: mixed-methods study. Eur J Cancer Care (Engl) 2012; 21: 548-559. http:// dx.doi.org/10.1111/j.1365-2354.2012.01345.x

[18] BIERI S, ROOSNEK E, HELG C, VERHOLEN F, ROBERT D, et al. Quality of life and social integration after allogeneic hematopoietic SCT. Bone Marrow Transplant 2008; 42: 819-827. http://dx.doi.org/10.1038/bmt.2008.253

[19] HEINONEN H, VOLIN L, UUTELA A, ZEVON M, BARRICK C, et al. Gender-associated differences in the quality of life after allogeneic BMT. Bone Marrow Transplant 2001; 28: 503-509. http://dx.doi.org/10.1038/sj.bmt.1703158

[20] WINGARD JR, HUANG IC, SOBOCINSKI KA, ANDRYKOWSKI MA, CELLA D, et al. Factors associated with self-reported physical and mental health after hematopoietic cell transplantation. Biol Blood Marrow Transplant 2010; 16: 1682-1692. http://dx.doi.org/10.1016/j.bbmt.2010.05.017

[21] WONG R, GIRALT SA, MARTIN T, COURIEL DR, Anagnostopoulos A, et al. Reduced-intensity conditioning for unrelated donor hematopoietic stem cell transplantation as treatment for myeloid malignancies in patients older than 55 years. Blood 2003; 102: 3052-3059. http://dx.doi.org/10.1182/ blood-2003-03-0855

[22] WATSON M, BUCK G, WHEATLEY K, HOMEWOOD JR, GOLDSTONE AH, et al. Adverse impact of bone marrow transplantation on quality of life in acute myeloid leukaemia patients; analysis of the UK Medical Research Council AML 10 Trial. Eur J Cancer 2004; 40: 971-978. http://dx.doi. org/10.1016/S0959-8049(03)00628-2

[23] LEE SJ, KIM HT, HO VT, CUTLER C, ALYEA EP, et al. Quality of life associated with acute and chronic graft-versus-host disease. Bone Marrow Transplant 2006; 38: 305-310. http:// dx.doi.org/10.1038/sj.bmt.1705434

[24] KISS TL, ABDOLELL M, JAMAL N, MINDEN MD, LIPTON $\mathrm{JH}$, et al. Long-term medical outcomes and quality-of-life assessment of patients with chronic myeloid leukemia followed at least 10 years after allogeneic bone marrow transplantation. J Clin Oncol 2002; 20: 2334-2343. http://dx.doi.org/10.1200/ LCO.2002.06.077

[25] PALLUA S, GIESINGER J, OBERGUGGENBERGER A, KEMMLER G, NACHBAUR D, et al. Impact of GvHD on quality of life in long-term survivors of haematopoietic transplantation. Bone Marrow Transplant 2010; 45: 1534-1539. http://dx.doi.org/10.1038/bmt.2010.5

[26] SYRJALA KL, LANGER SL, ABRAMS JR, STORER B, SANDERS JE, et al. Recovery and long-term function after hematopoietic cell transplantation for leukemia or lymphoma. JAMA 2004; 291: 2335-2343. http://dx.doi.org/10.1001/ jama.291.19.2335 
[27] MITCHELL SA, LEIDY NK, MOONEY KH, DUDLEY WN, BECK SL, et al. Determinants of functional performance in long-term survivors of allogeneic hematopoietic stem cell transplantation with chronic graft-versus-host disease (cGVHD). Bone Marrow Transplant 2010; 45: 762-769. http:// dx.doi.org/10.1038/bmt.2009.238

[28] FRASER CJ, BHATIA S, NESS K, CARTER A, FRANCISCO $\mathrm{L}$, et al. Impact of chronic graft-versus-host disease on the health status of hematopoietic cell transplantation survivors: a report from the Bone Marrow Transplant Survivor Study. Blood 2006; 108: 2867-2873. http://dx.doi.org/10.1182/blood2006-02-003954

[29] STEM CELL TRIALISTS` COLLABORATIVE GROUP. Allogeneic peripheral blood stem-cell compared with bone marrow transplantation in the management of hematologic malignancies: an individual patient data meta-analysis of nine randomized trials. J Clin Oncol 2005; 23: 5074-5087. http:// dx.doi.org/10.1200/JCO.2005.09.020

[30] Cutler C, Giri S, Jeyapalan S, Paniagua D, Viswanathan A, et al. Acute and chronic graft-versus-host disease after allogeneic peripheral-blood stem-cell and bone marrow transplantation: a meta-analysis. J Clin Oncol 2001; 19: 3685-3691.

[31] HOLZNER B, KEMMLER G, CELLA D, DE PAOLI C, MERANER V, et al. Normative data for functional assessment of cancer therapy--general scale and its use for the interpretation of quality of life scores in cancer survivors. Acta Oncol 2004; 43: 153-60 http://dx.doi.org/10.1080/02841860310023453

[32] BISHOP MM, BEAUMONT JL, HAHN EA, CELLA D, ANDRYKOWSKI MA, et al. Late effects of cancer and he- matopoietic stem-cell transplantation on spouses or partners compared with survivors and survivor-matched controls. J Clin Oncol 2007; 25: 1403-1411. http://dx.doi.org/10.1200/ LCO.2006.07.5705

[33] WETTERGREN L, SPRANGERS M, BJORKHOLM M, LANGIUS-EKLOF A. Quality of life before and one year following stem cell transplantation using an individualized and a standardized instrument. Psychooncology 2008; 17: 338-346. http://dx.doi.org/10.1002/pon.1240

[34] ANDRYKOWSKI MA, BISHOP MM, HAHN EA, CELLA DF, BEAUMONT JL, et al. Long-term health-related quality of life, growth, and spiritual well-being after hematopoietic stem-cell transplantation. J Clin Oncol 2005; 23: 599-608 http://dx.doi. org/10.1200/JCO.2005.03.189

[35] DEFOR TE, BURNS LJ, GOLD EM, WEISDORF DJ. A randomized trial of the effect of a walking regimen on the functional status of 100 adult allogeneic donor hematopoietic cell transplant patients. Biol Blood Marrow Transplant 2007; 13: 948-955. http://dx.doi.org/10.1016/j. bbmt.2007.04.008

[36] MELLO M, TANAKA C, DULLEY FL. Effects of an exercise program on muscle performance in patients undergoing allogeneic bone marrow transplantation. Bone Marrow Transplant 2003; 32: 723-728. http://dx.doi.org/10.1038/sj.bmt.1704227

[37] WEBSTER K, CELLA D, YOST K. The Functional Assesment of Chronic Ilness Therapy (FACIT) Measurement System: properties, applications, and interpretation. Health Qual Life Outcomes. 2003; 1: 79 http://dx.doi.org/10.1186/1477-7525$\underline{1-79}$ 